\title{
CO2 LASER THERAPY IMPROVING THE SEXUAL LIFE OF WOMEN AFTER BREAST CANCER TREATMENT (38 CASES)
}

Jackson Roberto de Moura', Jackline Zonta de Moura², Jackson Roberto de Moura Júnior³, Jardel Antônio da Silva Moura4 ${ }^{4}$ Áquilla Henrique Gonçalves Teixeira²

${ }^{1}$ Instituto da Mama de Ubá - Ubá (MG), Brazil.

2Universidade Federal de Ouro Preto - Ouro Preto (MG), Brazil.

${ }^{3}$ Universidade Federal de Minas Gerais - Belo Horizonte (MG), Brazil.

${ }^{4}$ Universidade Federal de Juiz de For a - Juiz de For a (MG), Brazil.

Objective: To verify the response to $\mathrm{CO} 2$ laser therapy in vaginal dryness among women submitted to treatment in a service in the State of Minas Gerais, Brazil. Methods: Descriptive, prospective case series study based on cases that were treated by the same staff from January 2019 to December 2019, storing predefined information and analyzing the data using the software R and SPSS PC. Results: Thirty eight women with mean age of 62.5 years + 9.1 (ranging from 48 to 82 years of age) were treated in the service for vaginal dryness. We observed total improvement of vaginal dryness in $94 \%$ of the cases. Improvement in sexual activity was observed in $83 \%$ of the cases, and increase in sexual relations, $71 \%$. The satisfaction with the treatment was of $95 \%$. We did not find statistical significance for the use of tamoxifen, anastrozole, previous chemotherapy and interval between surgery and laser therapy ( $p>0.05)$. Conclusion: The study shows good results of $\mathrm{CO} 2$ laser therapy in the improvement of vaginal dryness and sexual activity; however, the sample is limited for the statistical analysis of subgroups. 